\title{
Radiation Efficiency of Surface Burning on a Foam Metal Matrix with Ceramic Coating
}

\author{
Vladimir Shmelev \\ Combustion Laboratory, Institute of Chemical Physics RAS, Moscow, Russia \\ Email:shmelev.05@mail.ru
}

How to cite this paper: Shmelev, V. (2017) Radiation Efficiency of Surface Burning on a Foam Metal Matrix with Ceramic Coating. Energy and Power Engineering, 9, 366 385 .

https://doi.org/10.4236/epe.2017.97025

Received: June 16, 2017

Accepted: July 23, 2017

Published: July 26, 2017

Copyright (C) 2017 by author and Scientific Research Publishing Inc. This work is licensed under the Creative Commons Attribution International License (CC BY 4.0).

http://creativecommons.org/licenses/by/4.0/

\begin{abstract}
The modified empirical two-temperature model of surface burning on a foam metal matrix was proposed. The comparative experimental studies of radiation properties of both matrices without and with ceramic coating (alumina) were carried out. Measurement was conducted in different spectral ranges. The experimental results were compared with theoretical calculations. It was shown that the integral radiation efficiency of the matrix with ceramic coating was comparable with radiation efficiency of the matrix without any coating in the wide range of the firing rate and surpassed it on $30 \%-40 \%$ at firing rate above $50 \mathrm{~W} / \mathrm{cm}^{2}$.
\end{abstract}

\section{Keywords}

Burning Device, Metal Foam, Matrix, Radiation, Ceramic Coating

\section{Introduction}

Surface burning of a gas mixture on a permeable matrix is accompanied by strong IR radiation from the matrix surface. Radiation burners on the base of the surface burning are widely used in the industry. Radiation efficiency of surface burning is efficiency of the contribution of the radiation flux from the matrix surface in the total energy balance. Its increasing is the important problem for IR-burners. It can be provided by growing the matrix surface temperature. It was shown [1] [2] that coating the surface of a foam metal matrix with thin alumina or zircon film with lower thermal conductivity led to immersing the flame front into the matrix and growing the average temperature of the surface layer up to $150-200 \mathrm{~K}$. The ceramic coating improved the thermal strength of a matrix and resulted in expansion of the concentration limits of surface burning, reduced concentrations of the harmful impurities such as nitrogen oxide and carbon monoxide in the combustion products. 
However, to predict the radiation efficiency of the surface burning, i.e. contribution of the radiation flux from the surface of a foam metal matrix and its changing for matrix coated with the ceramic film are rather difficult. The difficulties are connected with founding exact physical characteristics of the matrix and properties of the ceramic coating. An alumina and zircon films have windows of optical transparency in the infrared spectral range. Therefore, integral radiation emissivity depends on the temperature, ceramics film thickness and spectral emissivity of the substrate i.e. from the matrix material. In our case, we focused on comparison of the surface burning on identic matrixes with ceramic coating and without one.

There are many theoretical publications concerning surface combustion on the uniform matrix (for example [3]), but matrix with ceramic coating was not considered yet. In the given study, the simple modified empirical theory is suggested and comparison of calculations with experiment upon radiation efficiency of surface burning on both matrices without and with the ceramic coating is conducted that allow us understanding the effect of the ceramic coating.

\section{Surface Combustion Model}

The simple empirical model was suggested in [4] permitting to calculate the thermal characteristics of the IR burning device with both matrices of flat and volumetric forms. The temperatures of the flame front and hot working surface of the matrix were found from consideration of the heat balance equation and term of the flame stationarity. For simplification of the solution the specific heat of gas was considered as a constant, and the temperature of gas, living the matrix was considered as equal to the temperature of the working matrix surface $T_{s H}$. Taking into account preheating of the gas mixture in matrix pores the empirical expression for flame rate was written as follows:

$$
U_{f}=A\left(T_{s H} / T_{0}\right)^{n} \exp \left[-\frac{E}{2 R T_{f}}\right]
$$

The temperature exponent $n$ was equal of 2 for methane [5]. The matrix surface temperature was determined by the single parameter of the problem $B=\frac{T_{0} \sigma \varepsilon}{c_{0} \rho_{0} A \eta_{s}}:$

$$
T_{\text {sH }}=\left(\frac{T_{a}-T_{f}}{B} \exp \left(-\frac{E}{2 R T_{f}}\right)\right)^{1 / 3} .
$$

The parameter $B$ determines also the critical value of firing rate when the burning failure occurs (impossibility of the solution (2)).

Appearance of surface permeability of the matrix $\eta_{s}$ in the parameter $B$ was stipulated by the assumption that the flame front rate in equilibrium was equal to the speed of expanded gas streams flowing out from channels or pores of the matrix, i.e. $U_{f}=U_{g}=\frac{U_{0} T_{g H}}{\eta_{g} T_{0}}$, where $\eta_{g}$-relative cross section of gas streams. If 
flame front is located close with the matrix surface at low speed of gas flow that it is possible to put $\eta_{g}=\eta_{s}$. If flame front is located far from the matrix surface at high speed of gas flow that the inequality $\eta_{g}>\eta_{s}$ is possible. A correction coefficient can be demanded because of this effect. This coefficient should be determined from comparison of calculations and experiments.

Distribution of the matrix temperature $T_{s}$ on coordinate $x$ in the matrix body at known value $T_{s H}$ was calculated separately by solution of the governing heat transfer equation within the framework of one-temperature model [1] [6] in the assumption of equality of gas and matrix temperatures in any cross-section across a gas flow. This solution is:

$$
T_{s}(x)=T_{s H}-\left(T_{s H}-T_{0}\right)[1-\exp (-b(H-x))] .
$$

Coordinates $x=0$ and $x=H$ correspond to the cold and hot matrix sides accordingly, the parameter $b$ is expressed through the specific mass consumption of the gas mixture $G=\rho_{0} U_{0}$, its specific heat and effective heat conductivity of the porous matrix $b=\frac{c_{0} G}{\lambda_{*}}$.

The given theory satisfactorily described the process of surface burning on ceramic permeable matrices with regular structure and on some foam metal matrices with low surface permeability [2] [3] at $\eta_{g}=\eta_{s}$.

At last time, the technology of metal foam production was developed so that matrices with high porosity and different topography of pores appeared [7] [8]. The calculation of the temperature distribution in the matrix body for such matrices can be not corrected at using one-temperature model. It is necessary to use the two-temperature model [9] [10] supposing that the gas temperature does not coincide with the solid phase temperature inside the matrix. However, because the heat transfer equations for a matrix and the energy balance equation for gas become coupled it is necessary to use the outlet gas temperature $T_{g H}$ instead of the surface matrix temperature $T_{s H}$ in the expression for burning rate (1):

$$
U_{f}=A\left(T_{g H} / T_{0}\right)^{n} \exp \left[-\frac{E}{2 R T_{f}}\right]=A K_{s}^{n}\left(T_{s H} / T_{0}\right)^{n} \exp \left[-\frac{E}{2 R T_{f}}\right],
$$

where the temperature coefficient is $K_{s}=\frac{T_{g H}}{T_{s H}}$.

The model described above should be updated thus that the own matrix structure could be taken into consideration because dependence of the parameter $\eta_{g}$ from gas speed can be possible. The matrix parameters appear through the value $T_{s H}$ in the two-temperature model, first of all, through the volumetric heat exchange coefficient between solid and gas phases, volumetric matrix porosity and also through the coefficient of radiation heat conductivity which is essential for high porosity matrices [10]-[15]. The volumetric heat exchange coefficient $\alpha_{v}=\frac{s \lambda_{g} N u}{d}$ is expressed through the specific surface of porous layer $s=\frac{6(1-\eta)}{d}$ and Nusselt number which can be chosen as $N u=0.725 \operatorname{Re}^{0.47} \operatorname{Pr}^{1 / 3}$ 
for small Reynolds numbers $\operatorname{Re}=2$ - 30 [10]. The coefficient of radiation conductivity can be determined from expression $\lambda_{r}=\frac{16 \sigma T_{s}^{3}}{3 k_{e}}$ [16] [17] [18]. According [11] the extinction coefficient can be found from expression $k_{e}=10^{-2}\left(0.715-0.206 \eta-0.459 \eta^{2}\right)$ PPI (where PPI is pores per inch).

The temperature profiles in solid and gas phases inside the matrix can be found from solution of two heat transfer equations for a matrix bulk and gas:

$$
\begin{aligned}
& \frac{\mathrm{d}^{2} T_{s}}{\mathrm{~d} x^{2}}-a_{1}\left(T_{s}-T_{g}\right)=0 \\
& \frac{\mathrm{d} T_{g}}{\mathrm{~d} x}-a_{2}\left(T_{s}-T_{g}\right)=0
\end{aligned}
$$

where $a_{1}=\frac{\alpha_{v}}{\lambda_{m}}, a_{2}=\frac{\alpha_{v}}{c_{0} G}$-parameters of the problem, $\lambda_{m}=\lambda_{*}+\lambda_{r}$ and effective thermal conductivity of porous matrix without taking into account of radiation transfer is $\lambda_{*}=\lambda_{0}(1-\eta) / 3$. The temperature dependence of the thermal conductivity of the solid phase can be neglected for simplification of the solution.

Boundary conditions: the gas temperatures $T_{g}=T_{0}$ and $\lambda_{m}\left(\frac{\mathrm{d} T_{s}}{\mathrm{~d} x}\right)_{x=0}=\varepsilon \sigma\left(T_{s 0}^{4}-T_{0}^{4}\right)$ at $x=0$ in supposing that the temperature gradient on the back (cold) side of the matrix $(x=0)$ is determined by radiation losses. At $x=H$ the temperature of the working surface of the matrix $T_{s H}$ is given by the value which must be found from solution of the energy balance equation for gas above the matrix surface.

The solution of the system (5) can be reduced to the solution of single equation of the second power:

$$
y^{\prime \prime}+a_{2} y^{\prime}-a_{1} y=0,
$$

where $y=\mathrm{d} T_{s} / \mathrm{d} x$.

The expression for derivative $y(x)$ and function $T_{s}(x)=\int y \mathrm{~d} x$ are obtained from consideration of (6):

$$
\begin{gathered}
y(x)=C_{1} \mathrm{e}^{k_{1} x}+C_{2} \mathrm{e}^{k_{2} x} \\
T_{s}(x)=\frac{C_{1}}{k_{1}} \mathrm{e}^{k_{1} x}+\frac{C_{2}}{k_{2}} \mathrm{e}^{k_{2} x}+C_{3}
\end{gathered}
$$

Here, $k_{1}=\frac{-a_{2}+\sqrt{a_{2}^{2}+4 a_{1}}}{2}, k_{2}=\frac{-a_{2}-\sqrt{a_{2}^{2}+4 a_{1}}}{2}$. Constants $C_{1}, C_{2}, C_{3}$ are found from boundary conditions: $C_{2}=\frac{T_{s H}-T_{s 0}+\frac{a_{3}}{k_{1}}\left(T_{s 0}^{4}-T_{0}^{4}\right)\left(1-\mathrm{e}^{k_{1} H}\right)}{\frac{1}{k_{1}}\left(1-\mathrm{e}^{k_{1} H}\right)-\frac{1}{k_{2}}\left(1-\mathrm{e}^{k_{2} H}\right)}$, $C_{1}=a_{3}\left(T_{s 0}^{4}-T_{0}^{4}\right), \quad C_{3}=T_{s 0}-\frac{C_{1}}{k_{1}}-\frac{C_{2}}{k_{2}}$, where $a_{3}=\varepsilon \sigma / \lambda_{m}$.

Solution (8) includes unknown value $T_{50}$, which one can be found by differentiation (7) and inserting the result obtained into the first equation of the system 
(5) at $x=0$ :

$$
C_{2}\left(k_{2}-k_{1}\right)+k_{1} a_{3}\left(T_{s 0}^{4}-T_{0}^{4}\right)=a_{1}\left(T_{s 0}-T_{0}\right)
$$

The gas temperature distribution in the matrix body is obtained from solution of the second equation of the system (5):

$$
T_{g}=\mathrm{e}^{-a_{2} x}\left(T_{0}+a_{2} \int_{0}^{x} T_{s}(x) \mathrm{e}^{a_{2} x} \mathrm{~d} x\right)
$$

Substituting the expressions (8) in (9), we have finally:

$$
T_{g}=\mathrm{e}^{-a_{2} x}\left[T_{0}+a_{2}\left(\frac{C_{1}}{k_{1}\left(k_{1}+a_{2}\right)}\left(\mathrm{e}^{\left(k_{1}+a_{2}\right) x}-1\right)+\frac{C_{2}}{k_{2}\left(k_{2}+a_{2}\right)}\left(\mathrm{e}^{\left(k_{2}+a_{2}\right) x}-1\right)+\frac{C_{3}}{a_{2}}\left(\mathrm{e}^{a_{2} x}-1\right)\right)\right]
$$

The heat balance equation above the working surface of the matrix is given as:

$$
\rho_{0} U_{0} c_{e}\left(T_{a}-T_{0}\right)=\rho_{0} U_{0} c_{p}\left(T_{f}\right)\left(T_{f}-T_{0}\right)+\varepsilon \sigma K_{l}\left(T_{f}\right) T_{s H}^{4}
$$

Here, dependence of the specific heat of combustion products on the temperature and occurrence of radiation losses from the back (cold) side of the matrix were taken into account. The effective specific heat of the mixture $c_{e}$ can be found from the relation $\frac{\rho_{m}}{\rho_{0}} \xi_{m} Q=c_{e}\left(T_{a}-T_{0}\right)$, where the concentration of combustible for methane-air mixture is $\xi_{m}=1 /(1+9.5 \alpha)$. Specific heat of the combustion products $c_{p}\left(T_{f}\right)$ can be represented as a linear function from the temperature $c_{p}\left(T_{f}\right)=c_{p 0}+\beta T_{f}$ in considered temperature range, and it can be accepted $c_{p 0} \approx c_{0}$ for simplification of calculations with adequate accuracy. Heat losses coefficient for the backside of the matrix in (11) is $K_{l}\left(T_{f}\right)=1+\left(\frac{T_{s 0}}{T_{s H}}\right)^{4}$.

Basically, the parameter $n$ in expression (4) is a function of the adiabatic combustion temperature $T_{a}$, i.e. $n=n\left(T_{a}\right)$. The expression (1) satisfactorily describes experimental data for methane-air mixture [5] at its leaning with air and heating up to the temperature $T_{g H}\left(K_{s}=1\right)$, if the function $n\left(T_{a}\right)$ is chosen as $n\left(T_{a}\right)=2.83-10 \xi_{m}=2.83-\frac{10}{9.5 \alpha\left(T_{a}\right)+1} \quad($ Figure 1).

Solution of the problem can be found with using (4), (8), (10), (11) and condition of flame front stationarity, i.e. equality of both speeds of the flame front and mixture flowing out from matrix pores. There is some peculiarity of metal foam having cells and channels of different size. The channels of small diameter penetrate in the large cells. It can be assumed that if flame front is located near the matrix surface its speed is equal to the speed of gas streams, which have size of the large cell diameter, i.e. $U_{f}=U_{g}=\frac{U_{0} T_{g H}}{\eta_{s} T_{0}}$. In other limit case, if the flame front penetrates into the near-surface cells its speed is equal to the speed of gas streams, which have size of the channel diameter. In common case this peculiarity can be taken into account by entering the correction function $\eta_{g}=\psi\left(U_{0}\right)$ in the expression for flame front stationarity which determines a geometry of the front: 


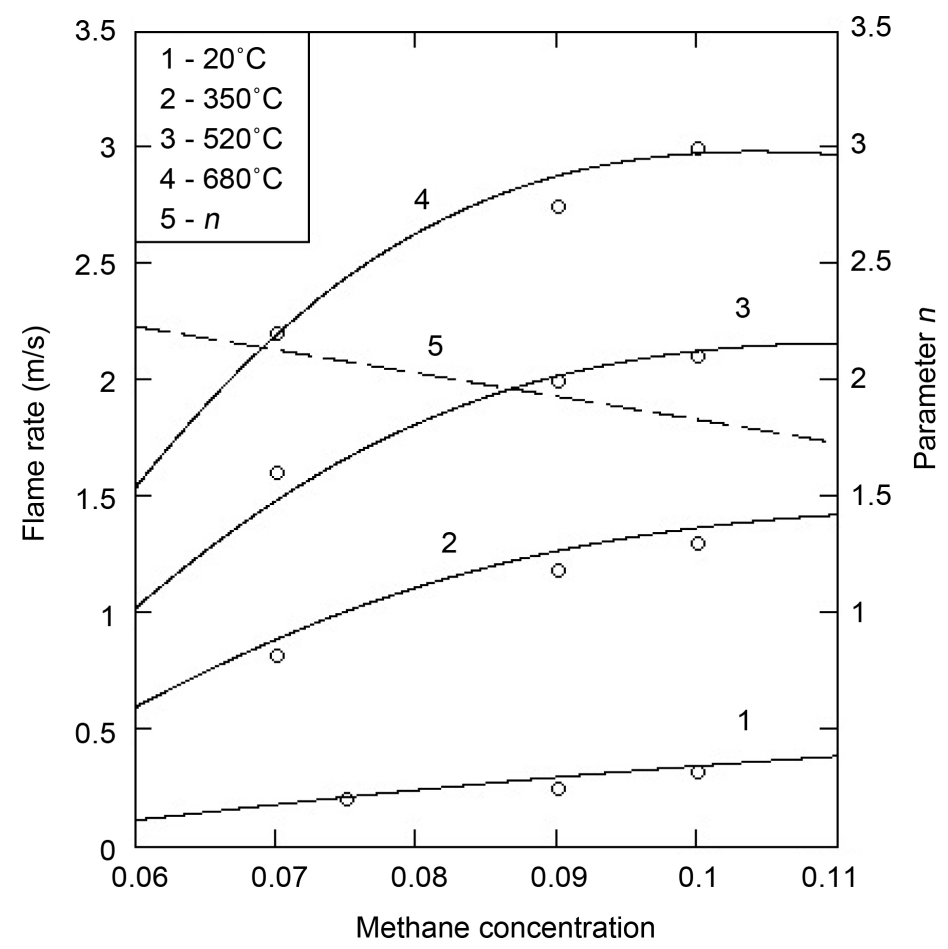

Figure 1. The parameter $n$ and burning rate of methane-air mixture at different initial temperature. Points: experiment (Hitrin, 1957); curves: calculation by Formula (4).

$$
U_{g}=U_{0} \frac{T_{g H}}{\psi\left(U_{0}\right) T_{0}}=U_{f} .
$$

For simplicity, the linear empirical function $\psi$ from speed $U_{0}$ can be chosen as:

$$
\psi\left(U_{0}\right)=\eta_{s 1}+\frac{\eta_{s 2}-\eta_{s 1}}{U_{02}-U_{01}}\left(U_{0}-U_{01}\right) .
$$

Here, $\psi\left(U_{0}\right)$ is actually equal to the surface matrix permeability in the speed range $U_{01}<U<U_{02}$. Parameters $\eta_{s 1}$ and $\eta_{s 2}$ are calculated for chosen matrix. Function $\psi\left(U_{0}\right)$ is equal the total relative area of large cells on the matrix surface $\eta_{s 2} \equiv \eta_{s}$ at the mixture speed $U_{02}$ which can be chosen as the critical value when the burning failure occurs. In this case, the value $U_{02}$ is found from solution of the problem. By the way it can be taken from experiment. In the other limit case $\psi\left(U_{0}\right)$ is equal the total relative area $\eta_{s 1}$ of small channels into the matrix cells at the mixture speed $U_{01}$ which can be chosen as zero.

The matrix surface temperature can be found as a function from the flame temperature which one in turn is expressed through the initial mixture speed $U_{0}$ $(4,12)$ :

$$
T_{s H}=\left(\frac{\left(T_{a}-T_{0}\right) c_{e} / c_{0}-\left(T_{f}-T_{0}\right)\left(1+\beta T_{f} / c_{0}\right)}{B_{1} F\left(T_{f}\right)} \exp \left(-\frac{E}{2 R T_{f}}\right)\right)^{1 /(5-n)} .
$$

Here, the parameter of the problem is $B_{1}=\frac{T_{0}^{n-1} \sigma}{C_{0} \rho_{0} A}$. The function $F\left(T_{f}\right)$ is ex- 
pressed through the function $\psi=\psi\left[U_{0}\left(T_{f}\right)\right]=\psi\left(T_{f}\right)$, temperature coefficient $K_{s}\left(T_{f}\right)$, radiation losses coefficient $K_{\lambda}\left(T_{f}\right)$ and through the emitting coefficient of the matrix surface $K_{e}$, which generally depends on the matrix surface temperature $K_{e}=K_{e}\left[T_{s H}\left(T_{f}\right)\right]=K_{e}\left(T_{f}\right): F\left(T_{f}\right)=\frac{K_{l}\left(T_{f}\right) K_{e}\left(T_{f}\right)}{\psi\left(T_{f}\right) K_{s}\left(T_{f}\right)}$. The function $F\left(T_{f}\right)$ can be found from solution of the equation system (5). It can be noted that $K_{s}\left(T_{f}\right)=1, K_{l}\left(T_{f}\right)=1, K_{e}=\varepsilon=$ const,$\psi=\eta_{s}$ for simplest case, for example, for ceramic matrix with channels [3]. The firing rate $w$ is expressed through the mixture speed and it is equal $w=\frac{Q \rho_{m}}{9.5 \alpha+1} U_{0}$ for the methane-air mixture.

\section{Calculation Results}

Parameters corresponding to the experimental conditions were used in our calculations. Main specifications of the solid phase: $H=8$ and $14 \mathrm{~mm}$, characteristic cell size $d=0.4 \mathrm{~mm}$, pores per inch of $60 \mathrm{PPI}, \eta=0.9, \eta_{s 1} \approx 0.1 \eta_{s 2} \approx 0.33$, thermal conductivity of Chromal $\lambda_{0}=20 \mathrm{Wm}^{-1} \cdot \mathrm{K}^{-1}, \varepsilon=0.9$ [19] [20]. Main specifications of the gas phase: $\alpha=1.05, \rho_{m} Q=3.6 \times 10^{7} \mathrm{~J} \cdot \mathrm{m}^{-3}$, $c_{0}=1.09 \times 10^{3} \mathrm{~J} \cdot \mathrm{kg}^{-1} \cdot \mathrm{K}^{-1}, \quad c_{e}=1.4 \times 10^{3} \mathrm{~J} \cdot \mathrm{kg}^{-1} \cdot \mathrm{K}^{-1}, \quad A=16.19 \mathrm{~m} \cdot \mathrm{s}^{-1}$, $E=1.47 \times 10^{5} \mathrm{~J} \cdot \mathrm{mol}^{-1} \cdot \mathrm{K}^{-1} \quad[5][10]$.

The surface and flame temperatures of the matrix as a function of firing rate is introduced in Figure 2 in assuming the constant emissivity $K_{e}=\varepsilon=0.9$ and for constant and variable function $\psi\left(U_{0}\right)$ (13). Theoretical results (limit case when the flame front area is equal to the matrix surface area) at $\psi=1$ were compared with experimental data [1] [2] [3] [6]. The surface temperatures obtained were found to be too high $\sim 1200-1300 \mathrm{~K}$ against of $900-1000 \mathrm{~K}$ in experiments at the typical power $w=40-60 \mathrm{~W} / \mathrm{cm}^{2}$. The critical value $w$ of flameout was also too large $w=162 \mathrm{~W} / \mathrm{cm}^{2}$ (Figure 2, curve 3 ).

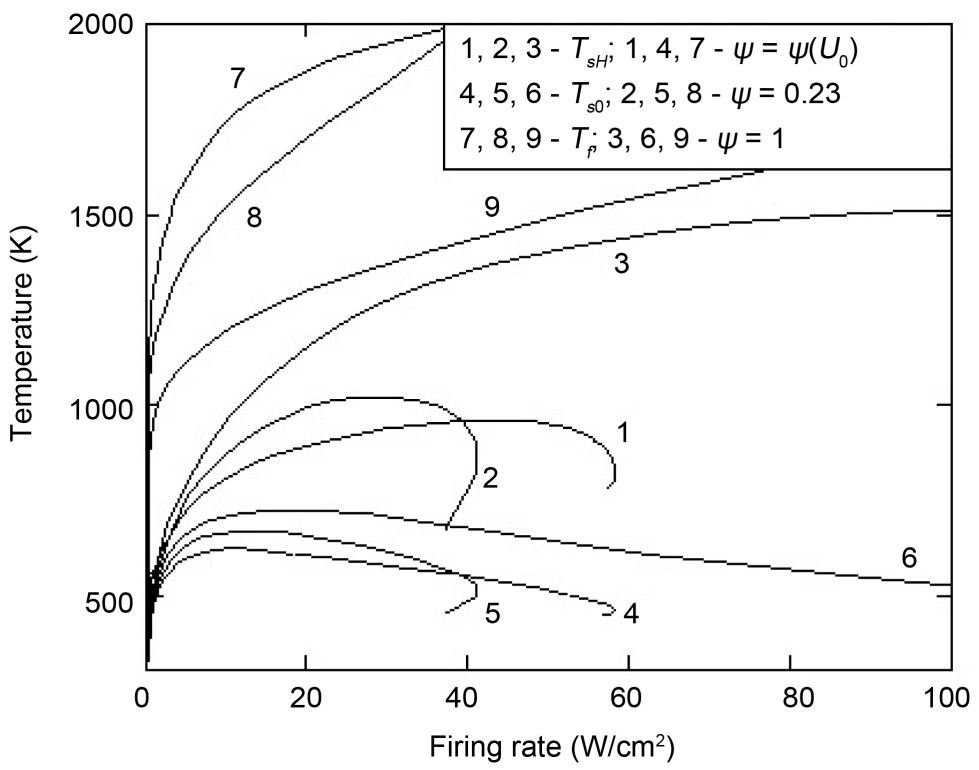

Figure 2. Temperatures of the matrix and flame. 
Reducing the parameter $\psi$ up to 0.23 decreases the temperature $T_{s H}$, however, dramatically reduces the critical value of firing rate $w=41 \mathrm{~W} / \mathrm{cm}^{2}$ (Figure 2, curve 2). Therefore, consideration of the parameter $\psi$ as a constant is in a contradiction with experimental data. The solution (14) depends only on the single indefinite parameter $\psi$ because the coefficients $K_{s}$ and $K_{l}$ are predetermined by solution of the system (5). The indicated contradiction can be overcome only by assuming dependence of the parameter $\psi$ on the mixture speed i.e. from the specific combustion power.

The solution (14) with expression $\psi=\psi\left(U_{0}\right)$ (13) most adequately describes experiment [1] [2] [3] (Figure 2, curve 1). Note, that dependence of backside matrix temperature $T_{s 0}(w)$ on the firing rate correlate with $T_{s H}(w)$ (Figure 2, curves 4 - 6). The flame temperature grows with increasing fire rate because the contribution of the radiation flux drops. The more flame temperature for given $w$ the lower value $T_{s H}$. The backside temperature of the matrix reduces because of intensive cooling of the matrix with the incoming cold mixture.

Comparative distributions of the temperature in solid and gas phases of the matrix of $8 \mathrm{~mm}$ thickness for variable $\psi$ and different firing rate are displayed in Figure 3(a). The function $\psi(13)$ used in calculations for variable geometry of the front flame is submitted by curve 1 in Figure 4. It can be seen in Figure 3(a) that $T_{s}>T_{g}$ for all considered variants. The more the surface temperature of the matrix and, therefore, the heat flux into the matrix the more the temperature difference. Note, the temperature coefficient is closed to unit even for $\psi=1$ (flat geometry of the flame front). For example, $K s=0.84$ at firing rate $W=40 \mathrm{~W} / \mathrm{cm}^{2}$. Dependence of the coefficient $K_{s}$ on firing rate for variable geometry of the flame front is presented in Figure 4. The difference between temperatures of the matrix surface and outlet gas grows with increasing $w$ because of reducing the contact time of gas and solid phases at increasing of the flow speed.

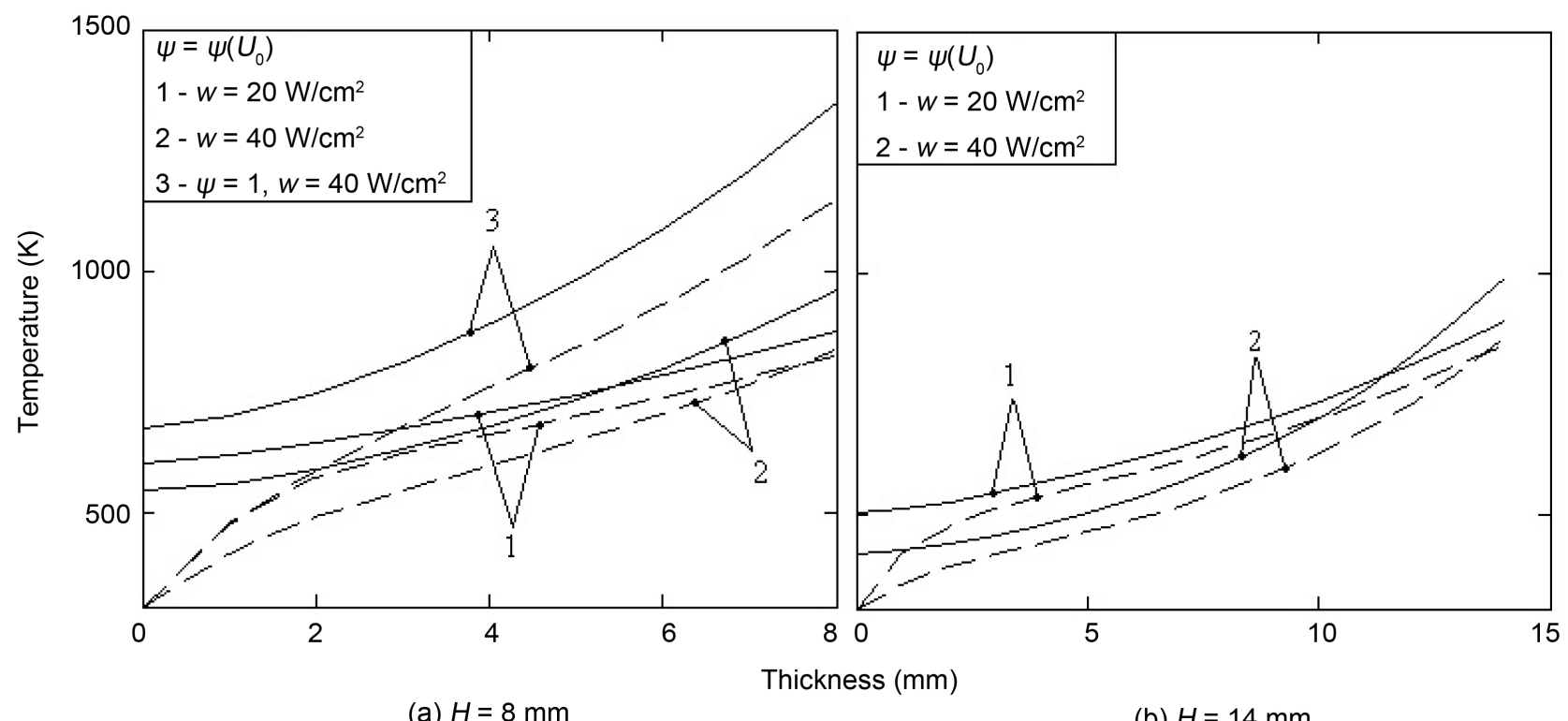

(a) $H=8 \mathrm{~mm}$

(b) $H=14 \mathrm{~mm}$

Figure 3. Temperature distributions in solid phase (continuous lines) and gas phase (dotted line). 


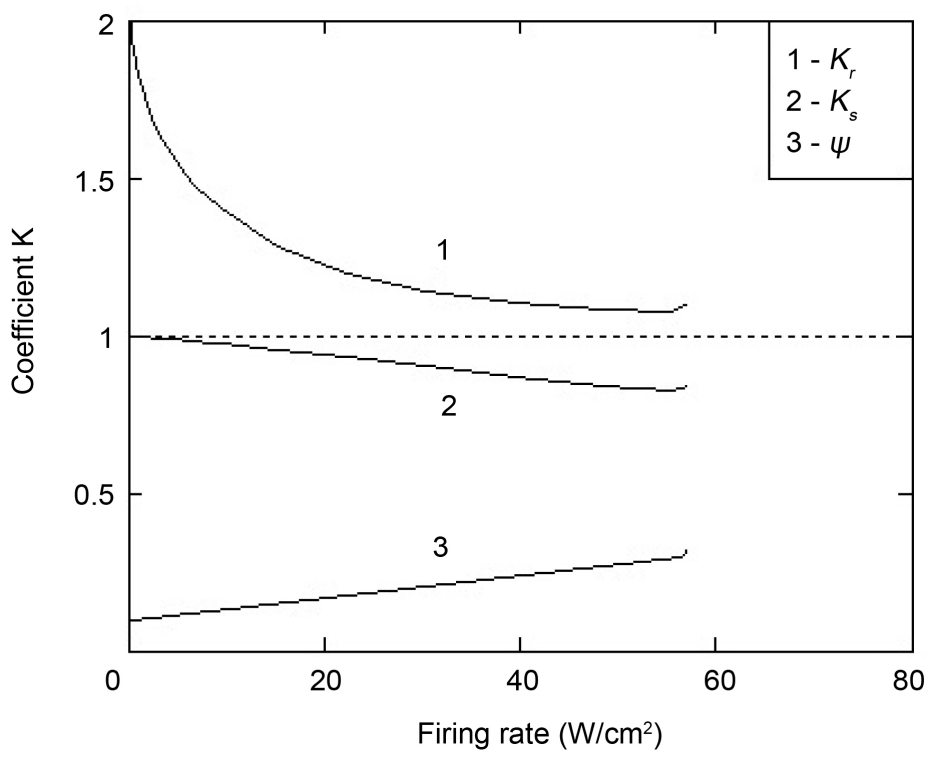

Figure 4. Coefficients for variable geometry of the flame front at $\alpha=1.05$.

Radiation losses from the backside of the matrix grow when $T_{50}$ approaches to $T_{s H}$ at reducing firing rate. They are approximately $10 \%$ in the area of $w \sim 40$ $\mathrm{W} / \mathrm{cm}^{2}$.

The similar result was obtained for thicker matrix of $14 \mathrm{~mm}$ thickness at variable geometry of the flame front (Figure 3(b)) but the matrix temperature of the working side appeared to be a little bit higher and the temperature of the back side much below in comparison with corresponding temperatures of the thin matrix. This fact is connected with reducing radiation losses from the backside of the thick matrix. The temperature coefficient is much closed to unit $K_{s}=0.94$ at $W=20 \mathrm{~W} / \mathrm{cm}^{2}$ and $K_{s}=0.88$ at $W=40 \mathrm{~W} / \mathrm{cm}^{2}$.

The suggested approach can be useful for analysis of the surface burning on matrices of different structure and material including with surface coating. It allows us to explain some particularities of the surface burning.

\section{Experimental Technic}

The matrices from metal foam (Chromal) of $8 \mathrm{~mm}$ thickness, with volumetric porosity about 0.9 , pore density of 60 PPI were used in the study. An elemental composition of metal: $\mathrm{Cr}-18 \%$; Al-6.5\%; Co-1.5\%; Fe-basic. Some matrices were coated with ceramic film (alumina) of the thickness $\sim 20 \mu \mathrm{m}$ (Figure 5 ) by using detonation dusting method [21].

The experimental studies were carried out using the model burner device with a removable plate matrix (Figure 6). The tested disk matrix of $60 \mathrm{~mm}$ diameter with armored side surface was fixed horizontally on the burner device. The punched disk distributor was established inside of the burner device for providing uniformity of the gas flow to the matrix.

The mixture of natural gas with air was formed in the mixer and flowed to the burner device. The ratio between components could be varied in the wide range. 


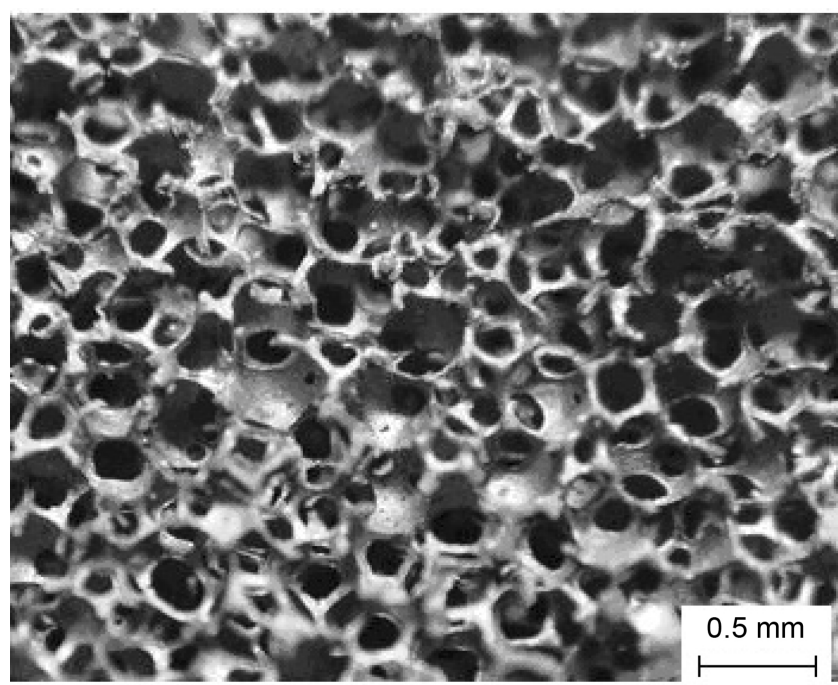

(a) without coating

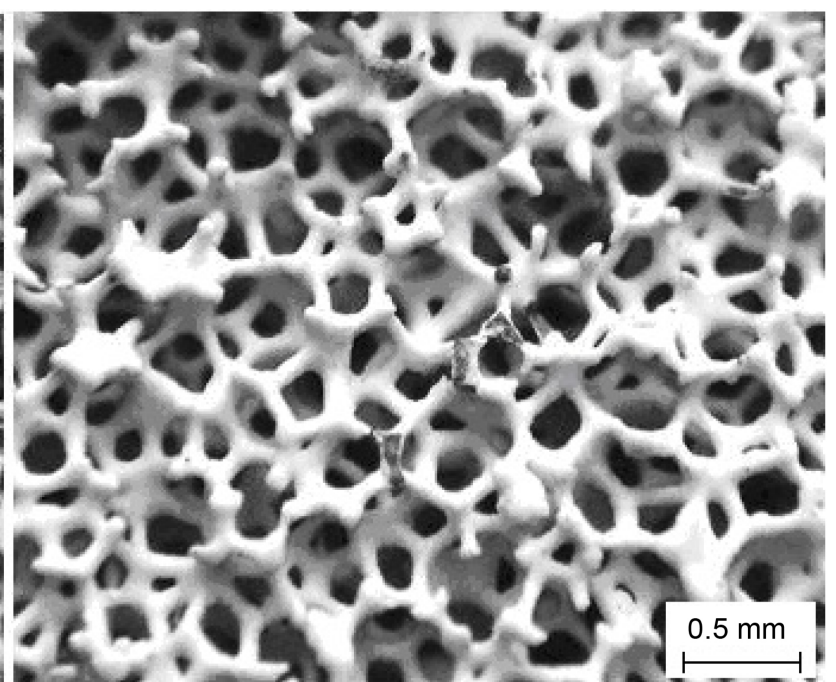

(b) with ceramic coating

Figure 5. The surface of metal foam matrices.

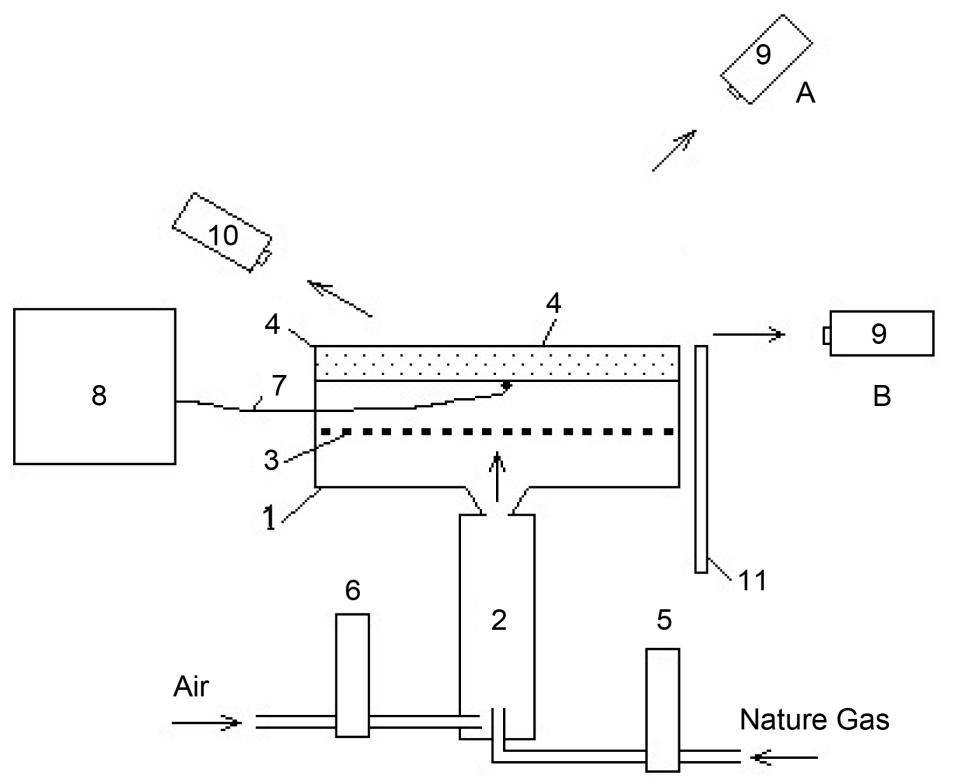

Figure 6. Scheme of experiments. 1: burner device; 2: mixer; 3: flow distributor; 4: matrix; 5, 6: flow meters; 7: thermocouple; 8: computer; 9: pyrometric sensor; 10: IR pyrometer; 11: heat protection screen.

That provided changing the air excess coefficient from 0.4 up to 2 , however, all experiments were conducted at $\alpha=1.05$. Gas and air consumptions were measured and regulated by F201AV and MV-304 flow meters (Bronkhorst High-Tech, USA) accordingly. Variations of the environmental temperature and pressure were not considered because of negligible in comparison of variation of nature gas pressure in the pipeline $(\sim 3 \%)$. The radiation pyrometer AR-882 IR (HM Digital Ltd., USA) with working wave range of $8-14 \mu \mathrm{m}$ was used to measure the radiation temperature of the matrix surface averaged over a surface area of $\sim 1 \mathrm{~cm}^{2}$ within the central part of the matrix. The temperature of the backside of 
the matrix was measured by alumel-chromel thermocouple of $0.3 \mathrm{~mm}$ thickness. The integral intensity of the radiation flux from the matrix surface was measured by pyrometric sensors IRA710ST1 and IRA-E420S1 in the spectrum from visible up to $14 \mu \mathrm{m}$ and from 5 up to $14 \mu \mathrm{m}$ accordingly. Record of the signals from the thermocouple and pyrometric sensors with using electronic converter E-270 (1-Card Ltd. Russia) was executed on the computer. The dispersion filters F1 and $\mathrm{F} 2$ in the narrow spectrum range of $1-3 \mu \mathrm{m}$ and $6-7 \mu \mathrm{m}$ accordingly were used for measurements of the spectral radiation flux. The filter F1 with trapezoidal transmittance had a transmittance plate in the wave range of $1.2-2.8 \mu \mathrm{m}$ and attenuation of 0.5 in wavelengths of 1 and $3 \mu \mathrm{m}$. The filter F2 with a bell-shaped transmittance had transmittance maximum in $6.6 \mu \mathrm{m}$ and attenuation of 0.5 in wavelengths of 6.2 and $7.2 \mu \mathrm{m}$.

The sensors were fixed aside from the burner at the distance of $400 \mathrm{~mm}$ from the matrix center at bevel way of $45^{\circ}$ to the horizontal (position A in Figure 6). It allowed us to avoid any heating of the sensors by the convective flow of the combustion products. Note, the radiation flux for given type of matrixes in chosen direction is almost same to the radiation flux in perpendicular direction to the matrix at firing rate less than $60 \mathrm{~W} / \mathrm{cm}^{2}$ [22]. The radiation flux was measured from both positions $\mathrm{A}$ and $\mathrm{B}$ in each experiment. The own radiation of the combustion products could be measured in horizontal plane of the matrix surface in the position B (Figure 6). The heat protection screen 11 cut off the radiation from the burner body. The own matrix radiation from the hot surface could be estimated as a difference of radiation fluxes in directions A and B. Apparently, the given method has not high accuracy of measurements because of anisotropy of the flame radiation. However, it was successfully used in [22] for measurement of absolute values of the radiation flux. In the given study, we confined itself by relative measurements of radiation fluxes that provided reliability results obtained. Summarized errors in the experimental study can be estimated as 5\%.

\section{Results and Discussion}

The experiments were carried out with both matrices without and with coating at different specific firing rate, which was varied from $\sim 20$ up to $60-80 \mathrm{~W} / \mathrm{cm}^{2}$. Damping or breaking-off of the flame occurred on the firing rate boundaries accordingly. The radiation temperature, radiation flux from the working surface of the matrix and also the backside temperature were measured in each experiment. The visible radiation from the surface of the matrix without coating was brighter than from matrix with ceramic coating. However, the temperature of the surface with ceramic coating measured by the IR pyrometer was above approximately on $100-200 \mathrm{~K}$ in all ranges of changing parameter $w$ (Figure 7). It is possible to explain such essential temperature difference by the fact that the flame front penetrates more deeply into the matrix bulk under the coat. The temperature of subsurface layer of the matrix grows. The radiation pyrometer registers increased effective temperature, as the ceramic coating is transparent in the wide IR radiation spectrum. The temperature of the back matrix side followed 


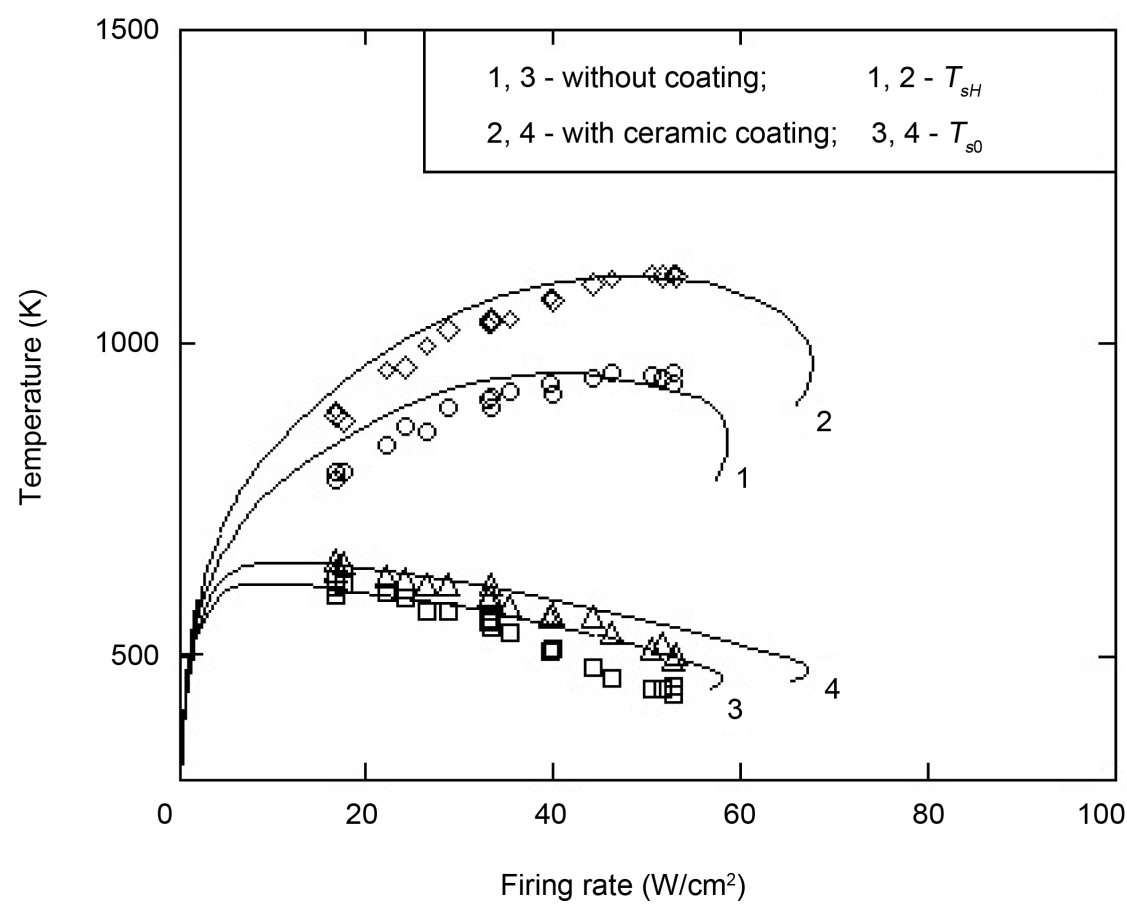

Figure 7. Working surface and backside surface temperatures of matrices. Points: experiment, curves: calculations.

the working surface temperature. The thermocouple showed higher temperatures for the matrix with coating (Figure 7). In both cases, the temperature reduced with increasing firing rate because of cooling the matrixes. The cooling effect was improved with growing the mixture consumption.

The experimental results obtained were compared with calculations (Figure 7) executed with taking into account different radiation emissivity for matrices without and with ceramic coating. The integral emissivity is almost constant and equals approximately of 0.9 in wide temperature range of $500-1400 \mathrm{~K}$ for heatresistant steels such as 0C18N12B-0C18U6A (Chromal), oxidized at high temperatures [23] [24] [25]. In too time, the integral emissivity of alumina reaches similar value only in the spectral range of $\sim 5-12 \mu \mathrm{m}$ [20] [23]. The data on integral emissivity of the thin alumina film on Inconel base are given in [23] [26]. The value $\varepsilon$ is changed from 0.78 up to 0.4 in the temperature range of 400 $1500 \mathrm{~K}$ accordingly though ceramic coating is almost transparent in the spectral range of $1-3 \mu \mathrm{m}$ corresponding to the maximum of $\sim 1000 \mathrm{~K}$ in the Planck temperature distribution. This experimental dependence $\varepsilon(T)$ for ceramic can be expressed by the function $\varepsilon=K_{e}\left(T_{s H}\right)=0.92-3.7 \times 10^{-4} T_{s H}$ which one was used in our calculations.

Comparison of experimental and computed results for both matrices is enough satisfactory taking into account simplicity of the model and some uncertainty in physical data for the matrices. Note that the temperature dependence for the working surface of the matrix on the parameter $w$ is smoothly, and the backside temperature is much lower for matrices of $14 \mathrm{~mm}$ thickness [1] but also fellows to our calculations. The temperature difference for the backside of 
both matrices without and with ceramic coating is also much less [3].

Radiation fluxes from the surface of both matrices without and with ceramic coating in wide and narrow $\left(\lambda_{1}<\lambda<\lambda_{2}\right)$ spectrum ranges were compared using the expression for radiation flux:

$$
J_{s}=\int_{\lambda_{1}}^{\lambda_{2}} \varepsilon(T, \lambda) \frac{C_{4} \lambda^{-5}}{\exp \left(\frac{C_{5}}{T_{s H} \lambda}\right)-1} \mathrm{~d} \lambda .
$$

Here, the constants $C_{4}=3.74 \times 10^{-16} \mathrm{~W} \cdot \mathrm{m}^{2}, C_{5}=1.439 \times 10^{-2} \mathrm{~m} \cdot \mathrm{K}$. Note, that the radiation flux measured with sensor IRA710ST1 is close to the full integral radiation flux because the maximum in the Planck temperature distribution for typical surface temperature of $\sim 1000 \mathrm{~K}$ lies near of $3 \mu \mathrm{m}$. The value of radiation flux measured in experiments is proportional to the sensor signal with the coefficient of proportionality, which can be found from comparison of calculated and experimental data. The experimental and calculated results for the integral radiation fluxes from the surface of both matrices are submitted in Figure 8. It can be seen that intensities of integral radiation fluxes for both matrices without and with ceramic coating are close to each other. The radiation efficiency for both cases lies in intervals of $10 \%$ - 13\%. The drop of calculated curves for large firing rates is connected with reducing the working surface temperature near the upper limit of the surface burning.

It was appeared that the radiation flux was almost twice above for the matrix with ceramic coating in comparison with the matrix without any coating in the spectral range $\lambda>5 \mu \mathrm{m}$ at all firing rate (Figure 9). In turn, this flux was approximately twice below than integral radiation flux (Figure $8(\mathrm{~b})$ ). It is connected with peculiarity of surface emissivity of the matrices in the given spectral range at high temperatures. The emissivity of heat resisting oxidized steel such

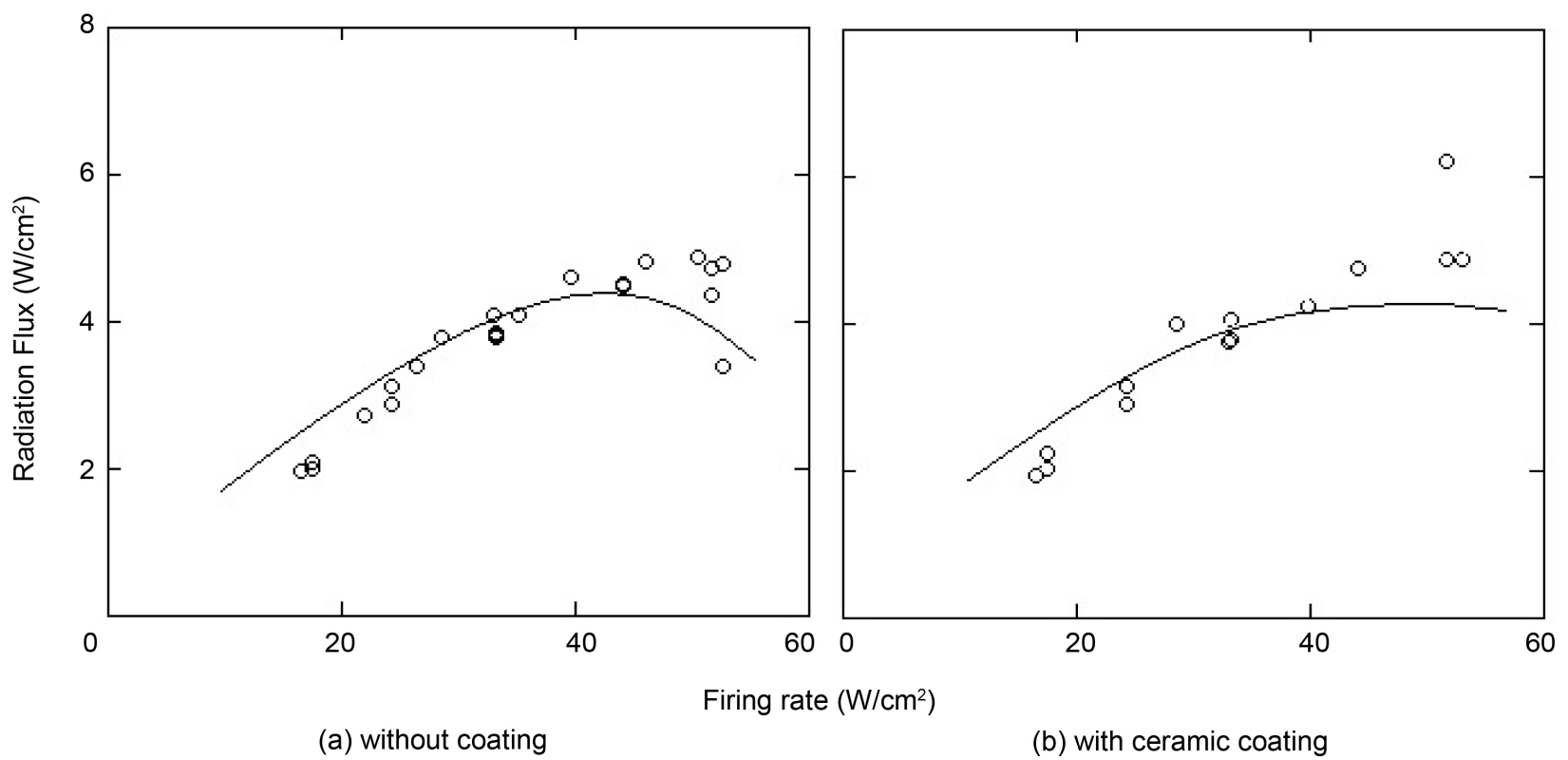

Figure 8. Integral radiation flux. Points: experiment, curves: calculations. 


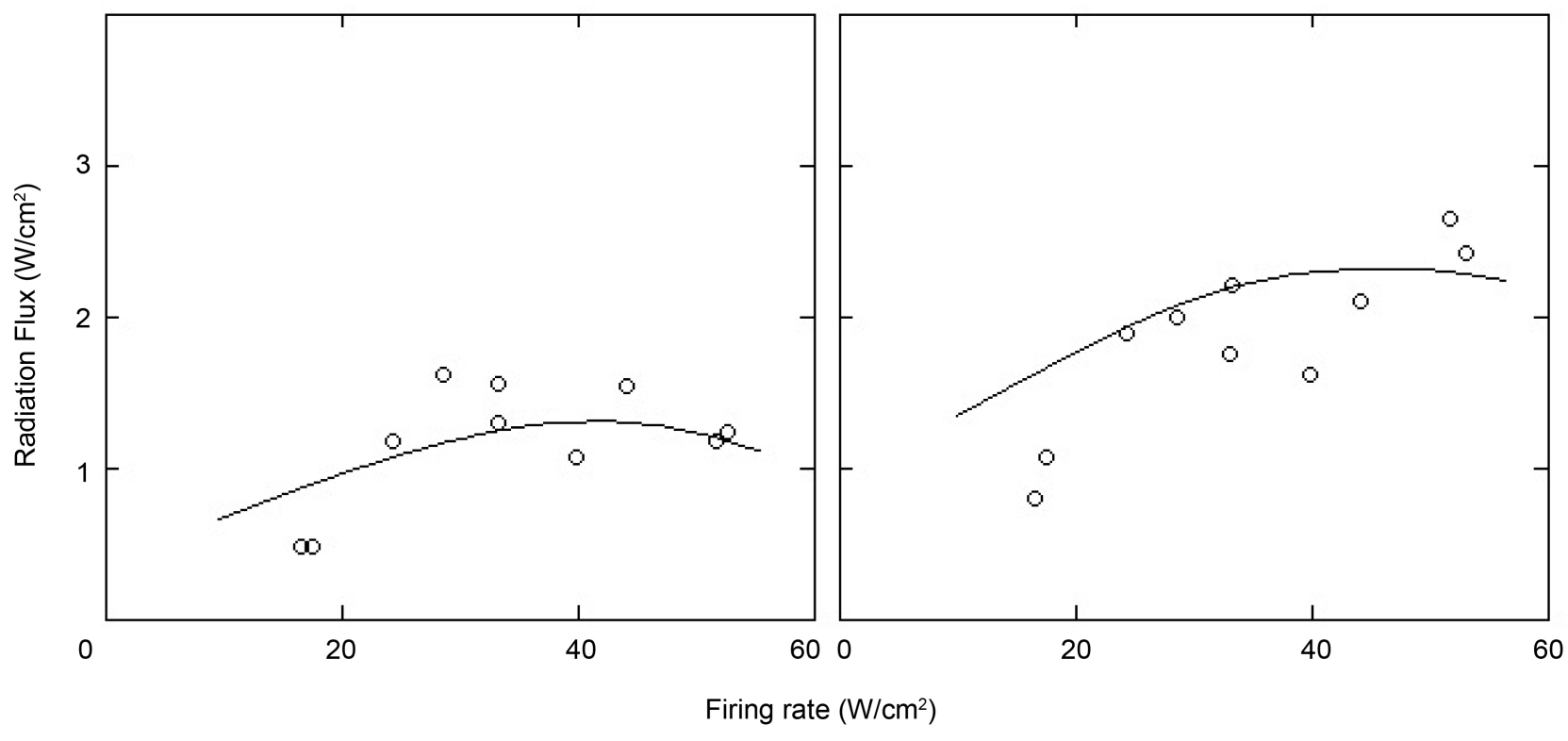

(a) without coating

(b) with ceramic coating

Figure 9. Radiation flux in the spectral range $\lambda>5 \mu \mathrm{m}$. Points: experiment, curves: calculations.

as Chromal for matrix without any coating reduces sharply up to value about $0.4-0.5$ with increasing wavelength from 5 up to $12 \mu \mathrm{m}$ [20] [23] [25]. This regularity can be presented as $\varepsilon(\lambda)=1.2-6 \times 10^{-2} \lambda$ at $\lambda>5 \mu \mathrm{m}$ in the temperature range of $\sim 800-1000 \mathrm{~K}$. Opposite, the ceramic emissivity reaches maximum value of $\sim 0.9$ [20] [23] [25].

Figure 10 illustrates the difference of radiation fluxes in some narrow spectral ranges for both matrices without and with ceramic coating. The radiation flux from the surface of the matrix with ceramic coating appears to be below than for the matrix without coating in the spectral range $1<\lambda<3 \mu \mathrm{m}$ (Figure 10(a)) where alumina has a transparency window at the own spectrum emissivity $\mathcal{E}=$ $0.1-0.2$ [20] [23] [25]. The theory satisfactorily describes experimental results for the matrix with coating if the surface emissivity is chosen as $\varepsilon=0.48-0.38$ in the temperature range of $600-1000 \mathrm{~K}$ accordingly at the temperature regularity $\varepsilon(T)$ for ceramics mentioned above. It can be explained by additional radiation from the base matrix layer (at high emissivity $\mathcal{E} \sim 0.9$ ) through the spectral transparency window of ceramics. Therefore, the effective surface emissivity of the matrix with thin ceramic film appears to be above than for thick ceramics.

The opposite effect is watched in the spectral range $6.2<\lambda<7.2 \mu \mathrm{m}$ where spectral transparency window for ceramics is absent (Figure 10(b)). The radiation flux from the surface of the matrix with ceramic coating was found to be above than from the matrix without coating because of higher the surface temperature. The theory satisfactorily describes experimental results for the matrix with coating if the tabular emissivity $\varepsilon=0.9$ for alumina is used in calculations.

Comparison of integral radiation fluxes for both matrices demonstrates that the relation of experimental and estimated radiation flux intensities $K$ is close to unit in the wide range of firing rate $10>w>50 \mathrm{~W} / \mathrm{cm}^{2}$ (Figure 11(a)). The value 


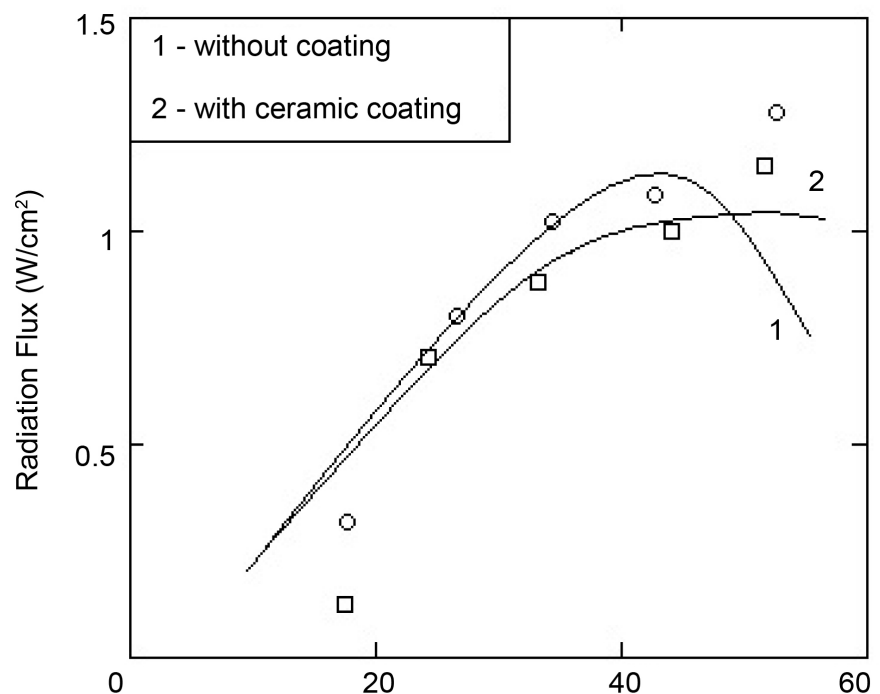

Firing rate $\left(\mathrm{W} / \mathrm{cm}^{2}\right)$

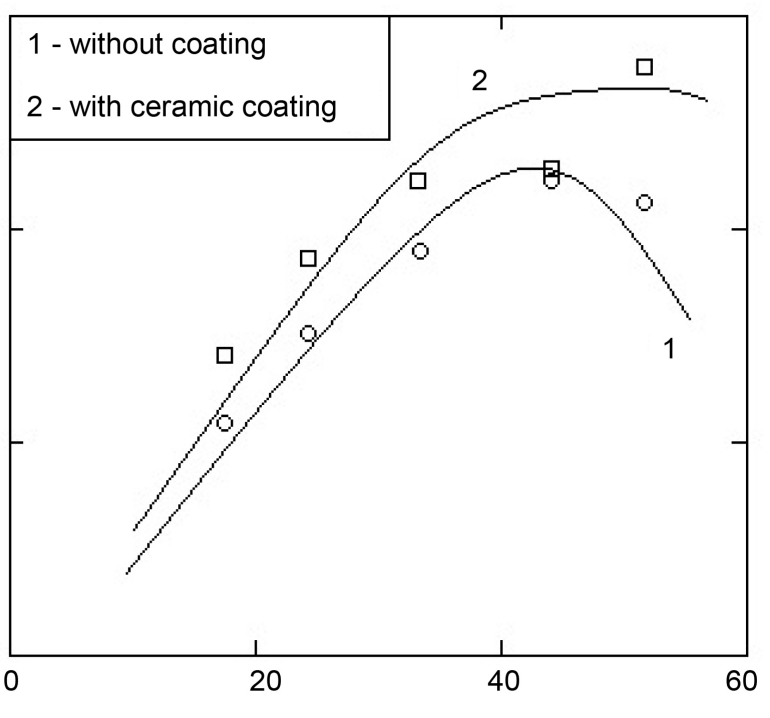

(b)

Figure 10. Radiation flux in the spectral range (a) $1<\lambda<3 \mu \mathrm{m}$ and (b) $6.2<\lambda<7.2 \mu \mathrm{m}$.

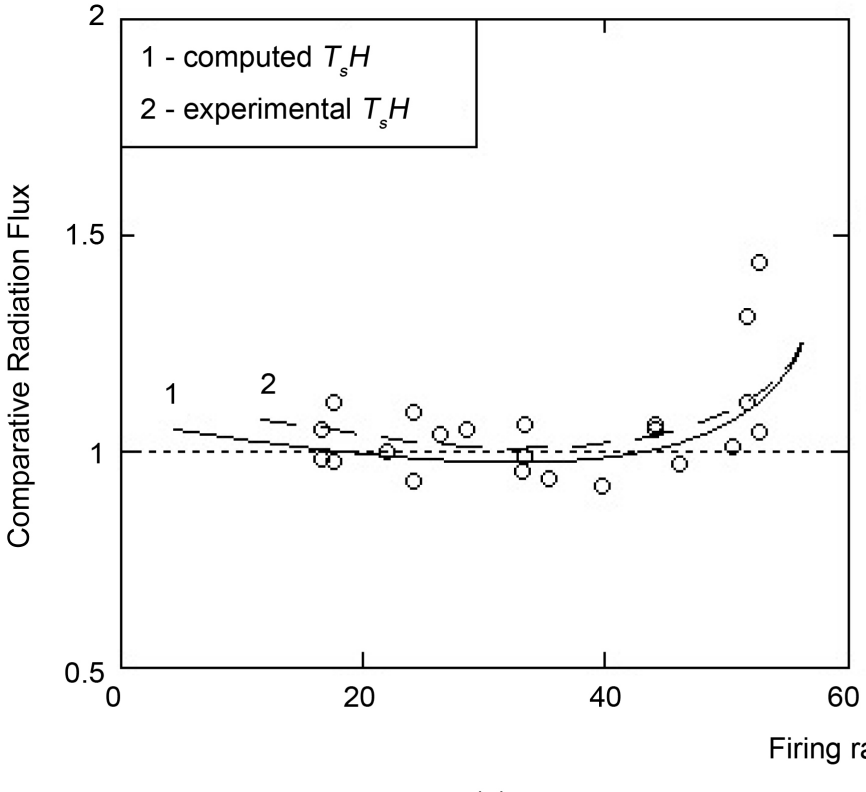

(a)

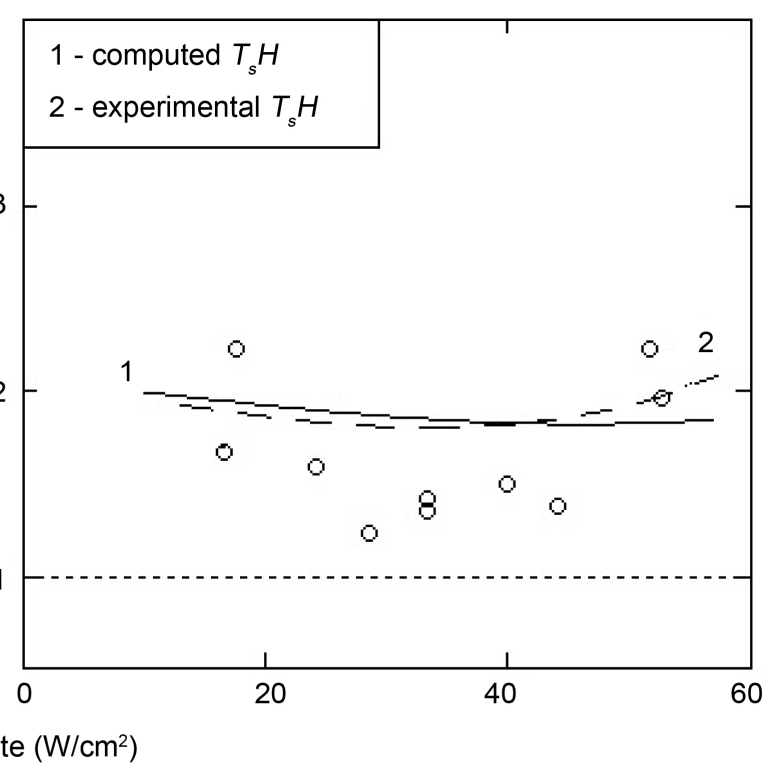

(b)

Figure 11. Relation of the radiation fluxes for spectrum (a) 2 - 14 and (b) 5 - $14 \mu \mathrm{m}$.

$K$ becomes notably more unit (up to 1.5 times) at $w>50 \mathrm{~W} / \mathrm{cm}^{2}$. It is connected with growing of the difference in the surface temperatures at increasing firing rate. .

Calculated values $K$ with using computed and experimental (Figure 7 ) data of surface temperatures and regularity $\mathcal{E}(T)$ are shown in same Figure 11(a). The satisfactory consent of calculations and experiments is visible. In the spectral range from 5 up to $14 \mu \mathrm{m}$ the relation $K$ reaches the large value of $\sim 1.5-2$ at all firing rates (Figure 11(b)). Calculated values $K$ with using computed and expe- 
rimental (Figure 7) data of surface temperatures are shown in Figure 11(b). The satisfactory consent of calculations and experiments is visible. Note, that the surface temperature was measured by the IR pyrometer just in the spectral region $8<\lambda<14 \mu \mathrm{m}$. Calculated curves reflect these measurements.

Thus, a metal foam matrix with ceramic coating is not worse in radiation efficiency than a matrix without any coating but noticeably surpasses it at specific firing rate $w>50 \mathrm{~W} / \mathrm{cm}^{2}$. Apparently, this fact is determined essentially with thickness of the ceramic coating. The integral surface emissivity will grow with reducing thickness of the ceramic film. However, the temperature of the matrix surface can be dropped.

\section{Conclusion}

The comparative analysis of the thermal and radiation characteristics of the surface burning on metal foam matrices was carried out. The modified two-temperature model for analytical finding the temperature distribution in gas and solid phases into the matrix body and the flame temperature was offered. It was shown that topographic particularities determining the heat exchange processes in the matrix body and the surface interaction of gas streams with the flame front have to be taken into account for metal foam matrixes. The analysis of radiation fluxes in different spectral regions with using of pyrometric sensors and dispersion filters was executed. Comparison of radiation properties of both matrices without and with ceramic coating was done. It was found that the integral radiation efficiency of the matrix with ceramic coating at surface burning was comparable with radiation efficiency of the matrix without any coating in the wide range of the firing rate and surpassed it on $30 \%-40 \%$ at firing rate $w>50 \mathrm{~W} / \mathrm{cm}^{2}$. The radiation efficiency of the matrix with ceramic coating is higher up to 2 times in the spectral range from 5 up to $14 \mu \mathrm{m}$.

\section{References}

[1] Shmelev, V. (2014) Surface Burning on a Foam Metal Matrix with the Ceramic Coating. Combust. Science and Technology, 86, 943-952.

https://doi.org/10.1080/00102202.2014.890601

[2] Vasilik, N. and Shmelev, V. (2015) Radiation Efficiency of IR Burners with a Foamed Metal Matrix with Ceramic Coating. In: Frolov, S.M., Ed., Combustion and Explosion, Torus Press, Moscow, 203-207.

[3] Krittacom, B. (2009) Studies on Thermal Characteristics of Open-Cellular Porous Burners. Ph.D. Thesis, Oita University, Oita.

[4] Shmelev, V. (2010) Combustion of Natural Gas at the Surface of a High Porosity Metal Matrix. Russian Journal of Physical Chemistry B, 4, 593-601. https://doi.org/10.1134/S199079311004010X

[5] Hitrin, L.N. (1957) Physics of Combustion and Explosion (In Russian). Moscow University, Moscow.

[6] Brjuhanov, O.N. (1977) Radiation-Convection Heat Exchange at Gas Burning in Perforated Systems. LGU, Leningrad.

[7] Han, X.-H., Wang, Q., Park, Y.-G., T'Joen, C., Sommers, A. and Jacobi. A. (2012) A Review of Metal Foam and Metal Matrix Composites for Heat Exchangers and Heat 
Sinks. Heat Transfer Engineering, 33, 991-1009. https://doi.org/10.1080/01457632.2012.659613

[8] Nawaz, K. (2011) Metal Foams as Novel Materials for Air-Cooling Heat Exchangers. Ph.D. Thesis, University of Illinois at Urbana-Champaign, Urbana, Illinois.

[9] Laevskii, Y.M. and Babkin, V.S. (1988) Filtration Combustion of Gases. In: Matros, U.Sh., Ed., Propagation of Heat Waves in Heterogeneous Mediums (In Russian), Nauka, Novosibirsk, 108-145.

[10] Futko, S.I. and Zhdanok, S.A. (2004) Chemistry of Filtration Gas Combustion. B.N., Minsk.

[11] Khantikomo, P. and Krittacom, B.A. (2011) Comprehensive Review on Thermal Radiation of Open Cellular Porous Materials. Naresuan University Engineering Journal, 6, 10-32.

[12] Lu, T.J., Stone, H.A. and Ashby, M.F. (1998) Heat Transfer in Open-Celled Metal Foams. Acta Materialia, 46, 3619-3635.

[13] Calmidi, V.V. and Mahajan, R.L. (1999) The Effective Thermal Conductivity of High Porosity Fibrous Metal Foams. Journal of Heat Transfer, 121, 466-471. https://doi.org/10.1115/1.2826001

[14] Ranut, P. and Nobile, E. (2014) On the Effective Thermal Conductivity of Metal Foams. Journal of Physics, Conference Series, 547, 1-11. https://doi.org/10.1088/1742-6596/547/1/012021

[15] Bhattacharya, A., Calmidi, V.V. and Mahajan R.L. (2002) Thermo-Physical Properties of High Porosity Metal Foams. International Journal of Heat and Mass Transfer, 45, 1017-1031.

[16] Tseng, P.-C. and Chu, H.-S. (2009) An Experimental Study of the Heat Transfer in PS Foam Insulation. Heat Mass Transfer, 45, 399-406. https://doi.org/10.1007/s00231-008-0417-1

[17] Loretza, M., Coquard, R., Baillis, D. and Maire, E. (2008) Metallic Foams: Radiative Properties/Comparison between Different Models. Journal of Quantitative Spectroscopy \& Radiative Transfer, 109, 16-27.

[18] Dobrego, K.V. and Zhdanok, S.A. (2002) Physics of Filtration Combustion of Gases. Luikov Heat and Mass Transfer Institute of the National Academy of Sciences of Belarus, Minsk. (In Russian)

[19] Zinoviev, V.E. (1989) Thermo Physical Properties of Metals at High Temperatures. Handbook, Metalurgia, Moscow. (In Russian)

[20] Goldsmith, A. (1961) Handbook of Thermophysical Properties of Solid Materials. Vol. 3, Pergamon Press, New York.

[21] Tjurin, J.N., Vasilik, N.J., Kolisnichenko, O.V., Kovaleva, M.G. and Prozorova, M.S. (2011) Expansion of Technological Possibilities of Installations of a Detonation Dusting. In: Frolov, S.M., Ed., Combustion and Explosion, Torus Press, Moscow, 3, 123-126.

[22] Kirdyashkin, A.I., Orlovskii, V.M. and Sosnin, A. (2010) Energy and Spectral Characteristics of Radiation during Filtration Combustion of Natural Gas. Combustion, Explosion and Shock Waves, 46, 523-527. https://doi.org/10.1007/s10573-010-0068-7

[23] Sheyndlin, A.E. (1974) Radiation Properties of Solid Materials. Handbook, Energiya, Moscow.

[24] Siegel, R. and Howell, J.R. (1978) Thermal Radiation Heat Transfer, 3rd Edition, CRC Press, Washington DC. 
[25] Kriksunov, L.Z. (1978) Handbook on Infrared Equipment. Sov. Radio, Moscow. (In Russian)

[26] Jorov, G.A. and Pavlovskaya, T.G. (1981) Radiation Spectrum of Oxited Metal Surface. High Temperature, 9, 912-918. (In Russian) 


\section{Nomenclature}

$A$ pre-exponential factor $(\mathrm{m} / \mathrm{s})$

$a_{1}$ parameter $\left(\mathrm{m}^{-2}\right)$

$a_{2}$ parameter $\left(\mathrm{m}^{-1}\right)$

$a_{3}$ parameter $\left(\mathrm{m}^{-1} \cdot \mathrm{K}^{-3}\right)$

$B$ parameter $\left(\mathrm{K}^{-2}\right)$

$B_{1}$ parameter $\left(\mathrm{K}^{\mathrm{n}-4}\right)$

$b$ parameter $\left(\mathrm{m}^{-1}\right)$

$C_{1}$ constant $\left(\mathrm{Km}^{-1}\right)$

$C_{2}$ constant $\left(\mathrm{Km}^{-1}\right)$

$C_{3}$ constant (K)

$c_{0}$ specific heat of the input mixture at constant pressure $\left(\mathrm{J} \cdot \mathrm{kg}^{-1} \cdot \mathrm{K}^{-1}\right)$ and temperature $T_{0}$

$c_{e}$ effective specific heat of mixture at constant pressure $\left(\mathrm{J} \cdot \mathrm{kg}^{-1} \cdot \mathrm{K}^{-1}\right)$

$c_{p}$ specific heat of combustion products at constant pressure $\left(\mathrm{J} \cdot \mathrm{kg}^{-1} \cdot \mathrm{K}^{-1}\right)$

$c_{p 0}$ specific heat of combustion products at constant pressure $\left(\mathrm{J} \cdot \mathrm{kg}^{-1} \cdot \mathrm{K}^{-1}\right)$ and temperature $T_{0}$

$d$ diameter of cells $(\mathrm{m})$

$E$ activation energy $\left(\mathrm{J} \cdot \mathrm{mol}^{-1}\right)$

$F$ function

$G$ specific mass consumption of mixture $\left(\mathrm{kg} \cdot \mathrm{s}^{-1} \cdot \mathrm{m}^{-2}\right)$

$H$ thickness of the matrix $(\mathrm{m})$

$J$ radiation flux $\left(\mathrm{W} \cdot \mathrm{m}^{-2}\right)$

$K$ relation of radiation fluxes

$K_{e}$ emitting coefficient

$K_{l}$ heat losses coefficient

$K_{s}$ temperature coefficient

$k_{e}$ extension coefficient $\left(\mathrm{m}^{-1}\right)$

$k$ coefficient in equations

$n$ power in expression for flame rate

$\mathrm{Nu}$ Nusselt number

Pr Prandtl number

$Q$-combustion energy of unit mass of combustible $\left(\mathrm{J} \cdot \mathrm{kg}^{-1}\right)$

$R$ universal gas constant $\left(\mathrm{J} \cdot \mathrm{mol}^{-1} \cdot \mathrm{K}^{-1}\right)$

Re Reynolds number

$s$ specific surface of porous layer $\left(\mathrm{m}^{-1}\right)$

$T_{0}$ initial gas temperature (K)

$T_{a}$ adiabatic temperature of combustion (K)

$T_{f}$ temperature of the flame front $(\mathrm{K})$

$T_{g}$ gas temperature in matrix body $(\mathrm{K})$

$T_{g H}$ outlet gas temperature above working surface of matrix (K)

$T_{s}$ temperature of solid phase in matrix body $(\mathrm{K})$

$T_{s 0}$ temperature of the cold surface (solid phase) of matrix (K)

$T_{s H}$ temperature of the hot working surface (solid phase) of matrix (K) 
$U_{0}$ input gas speed $(\mathrm{m} / \mathrm{s})$

$U_{f}$ flame front speed $(\mathrm{m} / \mathrm{s})$

$U_{g}$ gas speed above matrix surface $(\mathrm{m} / \mathrm{s})$

$w$ firing rate $\left(\mathrm{Wcm}^{-2}\right)$

$x$ coordinate in matrix body $(\mathrm{m})$

\section{Greek Symbols}

$\alpha$ air excess coefficient

$\alpha_{V}$ volumetric heat exchange coefficient $\left(\mathrm{W} \cdot \mathrm{m}^{-3} \cdot \mathrm{K}^{-1}\right)$

$\beta$ coefficient of proportionality $\left(\mathrm{J} \cdot \mathrm{kg}^{-1} \cdot \mathrm{K}^{-2}\right)$

$\mathcal{E}$ working surface emissivity

$\eta$ matrix porosity

$\eta_{g}$ relative cross section of gas streams

$\eta_{s}$ surface permeability of matrix

$\lambda_{0}$ thermal conductivity of matrix material $\left(\mathrm{W} \cdot \mathrm{m}^{-1} \cdot \mathrm{K}^{-1}\right)$.

$\lambda_{*}$ effective thermal conductivity of porous matrix $\left(\mathrm{W} \cdot \mathrm{m}^{-1} \cdot \mathrm{K}^{-1}\right)$

$\lambda_{g}$ thermal conductivity of mixture $\left(\mathrm{W} \cdot \mathrm{m}^{-1} \cdot \mathrm{K}^{-1}\right)$

$\lambda_{m}$ total thermal conductivity of matrix $\left(\mathrm{W} \cdot \mathrm{m}^{-1} \cdot \mathrm{K}^{-1}\right)$

$\lambda_{r}$ coefficient of radiation conductivity $\left(\mathrm{W} \cdot \mathrm{m}^{-1} \cdot \mathrm{K}^{-1}\right)$

$\lambda$ wave lengths $(\mu \mathrm{m})$

$\xi_{m}$ concentration of combustible

$\rho_{0}$ density of the input mixture $\left(\mathrm{kg} / \mathrm{m}^{3}\right)$

$\rho_{m}$ density of combustible $\left(\mathrm{kg} / \mathrm{m}^{3}\right)$

$\sigma$ Stefan-Boltzmann constant $\left(\mathrm{Wm}^{-2} \cdot \mathrm{K}^{-4}\right)$

$\psi$ function of surface flame correction

\section{Subscripts}

$1 ; 2 ; 3$ index

$a$ adiabatic

flame front

$g$ gas

$H$ surface coordinate

$m$ methane

$r$ radiation 
Submit or recommend next manuscript to SCIRP and we will provide best service for you:

Accepting pre-submission inquiries through Email, Facebook, LinkedIn, Twitter, etc. A wide selection of journals (inclusive of 9 subjects, more than 200 journals)

Providing 24-hour high-quality service

User-friendly online submission system

Fair and swift peer-review system

Efficient typesetting and proofreading procedure

Display of the result of downloads and visits, as well as the number of cited articles Maximum dissemination of your research work

Submit your manuscript at: http://papersubmission.scirp.org/

Or contact epe@scirp.org 